\title{
LA ANTROPOLOGÍA SPINOZIANA FRENTE A LA ANTROPOLOGÍA CARTESIANA
}

\author{
Daniel Moreno Moreno \\ IES Miguel Servet (Zaragoza) \\ dmoreno@unizar.es
}

\section{RESUMEN}

En el artículo se ponen frente a frente la antropología cartesiana-especialmente Les passsions de l'âme (1649) - y la antropología spinoziana expuesta en el manuscrito llamado Korte Verhandeling y en su Ethica (1677). Se comprueba la clara influencia de Descartes sobre Spinoza, pero se constata también la diferencia de fondo: el enfoque cartesiano es médico, psicológico y fisiológico mientras que el de Spinoza es teológico, lógico y moralista. Se ofrece además una nueva interpretación del famoso pasaje de la Ética donde Spinoza critica, no sin ironía, expresamente a su maestro Descartes.

Palabras Clave: mente, cuerpo, pasiones, Dios, inmortalidad, beatitud, Descartes, Spinoza.

\section{SPINOZIAN ANTHROPOLOGY VERSUS \\ CARTESIAN ANTHROPOLOGY}

\section{Abstract}

This paper confronts Descartes' anthropology -particularly Les passsions de l'âme (1649)and the anthropology that Spinoza expounds in his manuscript Korte Verhandeling and in his Ethica (1677). The great influence of Descartes upon Spinoza is detected, but their differences are discussed too: Cartesian views are medical, psychological and physiological; Spinozian views are theological, logical and moral. The paper focuses on the famous fragment of Ethics, where Spinoza quotes Descartes in order to criticize him, with a little irony.

Keywords: mind, body, passions, God, immortality, beatitude, Descartes, Spinoza. 
El lector atento de Laguna. Revista de Filosofía ya tiene noticia de la reinterpretación ofrecida en sus páginas de la antropología y la gnoseología cartesianas, así como de la particular lectura que Spinoza publicó sobre la teología de Descartes $^{1}$. Este artículo, por ello, continúa -y cierra- esa línea interpretativa abordando la antropología de Spinoza en comparación con la de Descartes. Se centrará en el análisis del Korte Verhandeling o Tratado breve, dado que, en su segunda parte, sigue muy de cerca Las pasiones del alma ${ }^{2}$ cartesianas, sin renunciar a las obligadas referencias a la $E_{t i c a}{ }^{3}$ spinoziana, donde queda expuesta la versión definitiva y en cuyo Prefacio a la parte v se encuentra la famosa crítica de Spinoza a la conclusión de la primera parte de Las pasiones del alma. Quedarán así contrapuestas ambas antropologías y se verá claramente hasta dónde sigue Spinoza a Descartes y cuándo se separa de su maestro.

\section{UN MANUSCRITO LLAMADO TRATADO BREVE}

Desde 1990 contamos en castellano con una estupenda edición, a cargo del esforzado Atilano Domínguez, de un manuscrito atribuido a Spinoza, encontrado y publicado en el siglo de XIX con el título Korte Verhandeling van God, de Mensch en des Zelfs Westand, esto es, Tratado breve de Dios, del hombre y de su felicidad ${ }^{4}$. El manuscrito incluye un Prefacio anónimo que lo presenta como traducción holandesa de un tratado en latín escrito por Spinoza. Dado que este tratado, de existir, se ha perdido, contamos sólo con la versión en holandés. Y pongo en cuestión la versión del presentador anónimo porque cuesta creer que Spinoza redactara un tratado y que este presentara el aspecto libre, oral, cargado de reexposiciones en notas, ordenado, sí, pero no al modo spinoziano, y con dos apéndices. Más bien parecen notas y bosquejos, sin duda de Spinoza, pero lejos de constituir un tratado. Está dividido en dos partes, sobre Dios y sobre el ser humano y su felicidad; compuestas a su vez por capítulos breves, al modo de sus Pensamientos metafísicos publicados, en 1663, junto a los Principios de la filosofía cartesiana ${ }^{5}$, pero sin su férreo ordena-

${ }^{1}$ Daniel Moreno, «Antropología cartesiana», Laguna, n. ${ }^{\circ} 38,2016$, pp. 19-36; «Gnoseología cartesiana», Laguna, n. ${ }^{\circ}$ 40, 2017, pp. 51-68, «El Descartes de Spinoza», Laguna, n. ${ }^{\circ} 42,2018$, pp. 29-46.

2 Cf. René Descartes, Las pasiones del alma, traducción de José Antonio Martínez Martínez, Madrid, Tecnos, 2010. En adelante P.

${ }_{3}$ Cf. Baruch de Espinosa, Ética demostrada según el orden geométrico, traducción de Vidal Peña, Madrid, Editora Nacional, 1979. La edición original latina, según la edición de Carl Gebhardt, se encuentra disponible en http://spinoza.tk. En adelante E.

${ }^{4}$ Cf. Spinoza, B., Tratado breve de Dios, del hombre y de su felicidad, Madrid, Alianza Editorial, 1990. La versión en holandés, según la edición de Carl Gebhardt, se encuentra disponible en http://spinoza.tk. En adelante utilizaré la abreviatura habitual, procedente del título holandés: KV.

${ }^{5}$ Cf. Spinoza, B., Principios de filosofía de Descartes y Pensamientos metafísicos, recogido en Tratado de la reforma del entendimiento/Principios de filosofía de Descartes/Pensamientos metafisicos. Edición de Atilano Domínguez. Madrid, Alianza Editorial, 1988. 
miento lógico. Además, la primera parte presenta, entremetidos, dos breves Diálogos -género tan del gusto humanista-, pero que Spinoza apenas pule. Por el contenido, ambas obras están íntimamente ligadas, es más, se suponen mutuamente. Si en la obra publicada, Spinoza se centra en la teología, no por ello deja de dar a conocer, sucintamente, toda una antropología; y en el Tratado breve, si bien comienza con la teología, deja a un lado lo principal, esto es, la esencia y definición de Dios -el tema principal de los Pensamientos metafísicos-, y se centra en la crítica a las tres sustancias cartesianas y en los atributos de Dios, ya propios, como ser causa necesaria de todo y providencia, ya no propios, esto es, atribuidos por la escolástica a Dios en base a las características del ser humano, como: ser omnisciente, misericordioso, sabio o el bien supremo. La parte primera, así, sienta las bases teológicas de la antropología, expuesta en la segunda parte.

La distinción cartesiana de tres sustancias, hecha con la salvedad de que tanto la res cogitans como la res extensa no se bastan a sí mismas para existir sino que necesitan de la res infinita, o Dios, que es la única cuya esencia implica la existencia, le da pie a Spinoza para afirmar que, en realidad, sólo hay una sustancia, Dios o Ser. Las otras dos, el Pensamiento y la Extensión, y otras infinitas que ha de haber, no son más que modos o atributos ${ }^{6}$. La prudente posición cartesiana que aseguraba lo más importante para él, esto es, la distinción de lo mental y lo extenso, la no corporalización del alma -lo que le llevó, precisamente, a introducir el neologismo $m e n s^{7}-$, se convierte, en manos de Spinoza, en fuente de un cúmulo de contradicciones dado que una sustancia no puede ser causa de otra o, de haber varias, no podría haber relación entre ellas, etc. Entre muchos textos posibles valga esta formulación: «Yo veo claramente -habla la Razón, en el primer Diálogo- que sólo hay un Uno, el cual existe por sí mismo y es el sujeto de todos los demás atributos. Y, si quieres llamar sustancias a lo corpóreo y a lo pensante en relación a los modos que de ellos dependen, hazlo, pero después debes también llamarlos modos en relación a la sustancia de la que ellos dependen; pues no han sido concebidos por ti -la Concupiscencia, trasunto de Descartes- como existentes por sí mismos» (KV 72-73).

De este modo, Spinoza lleva a su extremo la táctica cartesiana de quitar entidad ontológica a todas las instancias universales con las que la escolástica, basándose en Platón y en Aristóteles, había poblado el mundo. Para Spinoza todas son meros entes de razón, esto es, nada: «Todas las cosas particulares y sólo ellas tienen causa, y no las generales, que no son nada» (KV 88). Sólo hay, por tanto, seres particulares ordenados y causados por Dios, que es causa intrínseca de todas las cosas.

${ }^{6} C f$. «La res cogitans y la res extensa o son atributos de Dios o afecciones de los atributos de Dios» (E, I, 14, corolario II).

${ }^{7}$ Es sabido que Spinoza sigue a Descartes en el uso de mens en lugar de anima para evitar confundir lo mental con la forma del cuerpo, con la vida o sangre del cuerpo o con fantasmas y espíritus. Sin embargo, ni los traductores franceses de Descartes ni los traductores holandeses de Spinoza estuvieron al tanto del matiz y tradujeron mens como alma -âme, ziel-o como espíritu -esprit, geest-, lo que ha generado no pocos problemas interpretativos, especialmente cuando se pregunta cómo es posible que el alma se desligue del cuerpo y sea inmortal. 
Las instancias intermedias son constructos conceptuales 8 . La naturaleza consta de particulares que, si son movimientos, se encuadran en la Extensión; si son ideas, en el Pensamiento. Los múltiples géneros, y sus diferencias, de los que habla la escolástica -junto con nociones como bien, mal, orden, confusión, calor, frío, belleza, feal$\mathrm{dad}^{9}$ - son meras palabras. Y llama la atención que Spinoza llame al Pensamiento y a la Extensión «hijo, hechura o creación inmediata de Dios, también creado por él desde toda la eternidad y que permanece inmutable por toda la eternidad» (KV 94) porque son formulaciones muy cercanas a la Trinidad cristiana, donde Dios es Dios y también Logos -Extensión- y Spiritus -Pensamiento-.

\section{SPINOZA LECTOR DE LAS PASIONES DEL ALMA CARTESIANAS}

Así como en los Principios de la filosofía cartesiana Spinoza se muestra como un gran conocedor, si bien crítico, de Descartes, en concreto de sus Principia philosophiae (1644), en la segunda parte del Tratado breve es manifiesta la huella de las cartesianas Passions de l'âme (1649), que Spinoza leyó en su versión latina Passiones animae per Renatum Des Cartes (1650), que incluía como título de la Primera parte Passiones, sive affectus animae ${ }^{10}$, es decir, la equiparación de pasiones y afectos, donde el original decía simplemente Les Passion de l'Ame. Descartes había dividido su obra en tres partes, la primera dedicada a la naturaleza del ser humano, y la segunda y la tercera propiamente a su estudio de las pasiones. También Spinoza expone la antropología que se deriva de su teología, primero, antes de pasar a la clasificación de las pasiones. En ambos casos sigue de cerca a Descartes, aunque con matices propios.

\subsection{Mente y Cuerpo, dos Caras de la misma moneda}

Sirva este apretado resumen de la antropología cartesiana: en el ser humano se pueden distinguir su cuerpo y su alma; al cuerpo le corresponde el calor y el movimiento, al alma los pensamientos; es un error -es el error, se podría decir-creer que

${ }^{8}$ Las implicaciones políticas de esta limpieza ontológica se exponen en el Tratado teológico-politico (1670), donde las sectas y los grupos religiosos o gremiales, con sus jurisdicciones propias, se ven como obstáculos al poder omnímodo del Estado, que debe legislar sólo para individuos autónomos y libres, que son ciudadanos en tanto que miembros del Estado, del mismo modo que las cosas son seres en tanto que son creaturas de Dios.

9 Cf. E, I, apéndice, p. 101. El finalismo, rechazado por Lucrecio, había sido por Descartes si no criticado abiertamente como hace Spinoza, sí puesto entre paréntesis como innecesario, incluso como pretencioso por parte de los humanos que pretenden conocer las intenciones divinas.

${ }^{10}$ La versión latina puede consultarse en https://gallica.bnf.fr/ark:/12148/btv1b86120184. image. Que Spinoza utilizó esa versión latina se puede comprobar cotejando la definición cartesiana de las pasiones que Spinoza cita literalmente en E 355 y que corresponde al artículo 27 de Las pasiones del alma. 
el alma da movimiento, calor o vida al cuerpo; el cuerpo consta de órganos como el corazón, los nervios, sangre en circulación, etc., a través de los nervios se mueven los espíritus animales, que son corpúsculos procedentes de la parte más sutil de la sangre que llegan al cerebro y que originan el movimiento muscular y la sensación; al alma le corresponden sólo los pensamientos; el alma es activa cuando quiere y pasiva cuando percibe cosas, en ambos casos puede tener como objeto a sí misma o a Dios, o a cosas materiales, como el cuerpo propio o los objetos externos; las percepciones de olor o color las referimos a otros cuerpos, las de hambre o calor al cuerpo propio y las de alegría o ira al alma; estas últimas se llaman, propiamente, pasiones y muestran «la estrecha alianza que existe entre el alma y el cuerpo» (P 96); "el alma ejerce inmediatamente sus funciones» (P 103) no en el corazón, sino en el cerebro, en una pequeña glándula situada en su centro; los combates entre distintas pasiones se deben a impulsos contrarios que afectan a esa glándula; la fortaleza del alma respecto a las pasiones procede del conocimiento verdadero.

Spinoza acepta este planteamiento general en el Tratado breve, como se ve en comentarios al paso: «Ningún modo del pensamiento puede producir movimiento o reposo en el cuerpo. No obstante, de acuerdo con lo que observamos en nosotros $^{11}$, puede muy bien suceder que un cuerpo, que actualmente se mueve hacia un lado, llegue a moverse hacia el otro lado [...]. La causa de todo esto, y no puede ser otra, es que la mente, por ser una idea del cuerpo, está tan unida con él que ella y ese cuerpo así constituido forman juntos un todo» (KV 143), «la tristeza es causada por el amor y la unión que ella [la mente] tiene con el cuerpo» (KV 148), «la pérdida de algún bien [...] hace que los espíritus se junten en torno al corazón y que con la ayuda de otras partes lo compriman y lo cierren, justamente al contrario de lo que sucede con la alegría. Al percibir la mente reiteradamente esta presión, siente dolor. [...] Ahora bien, esto no puede significar una acción inmediata del vino sobre la mente, sino tan sólo del vino sobre los espíritus» (KV 148, nota). De hecho, la objeción a la que Spinoza responde, respecto a la unión de mente y cuerpo, no es cómo es posible que lo mental afecte a lo extenso, dado que él entiende bien a Descartes, sino por qué la mente no puede mover una piedra o el cuerpo de otra persona; su respuesta es clara: «Si bien la naturaleza tiene diversos atributos, ella no es más un ser, del que se predican todos esos atributos», es decir la res cogitans y la res extensa son dos caras de un única moneda, por lo que, obviamente, la mente de Pedro no puede mover a Pablo (cf. KV 150-151). En la Ética presenta las mismas ideas con una formulación propia, y más clara: «La sustancia pensante y la sustancia extensa son una sola y misma sustancia, aprehendida ya desde un atributo ya desde

11 Spinoza distingue perfectamente los dos puntos de vista: como metafísico ha de negar la acción de la mente sobre el cuerpo y del cuerpo sobre la mente, aunque, hablando «de acuerdo con lo que observamos en nosotros», es decir, desde la mente, todos somos conscientes de querer mover el brazo y moverlo, pero no es la mente la que, físicamente, lo mueve, sino los espíritus animales del cuerpo. Del mismo modo, «el efecto principal del otro atributo es un concepto de las cosas, del cual surgirá, de acuerdo con lo por él percibido, o el amor o el odio, etc. Dado que estos efectos no llevan consigo ninguna extensión, no pueden ser atribuidos a esta, sino exclusivamente al pensamiento» (KV 143). 
otro. Así también, un modo de la Extensión y la idea de dicho modo son una sola y misma cosa, pero expresada de dos maneras» (E 115); "la mente y el cuerpo son una sola y misma cosa» (E 186) ${ }^{12}$. Pero considero que lo importante son los puntos de fricción, que son los que, lógicamente, destaca Spinoza. El primero de los cuales, y más importante, enlaza con la metafísica y afecta nada menos que a la misma entidad del ser humano.

\subsection{ENTIDAD ONTOLÓGICA DEL SER HUMANO}

Del mismo que la res cogitans y la res extensa pierden en el planteamiento spinoziano su entidad de sustancias y quedan absorbidas en la res infinita como dos de sus atributos infinitos, el propio ser humano y sus facultades pierden entidad sustancial. La limpieza ontológica implícita en la afirmación de que sólo Dios es propiamente en tanto que es la única esencia que implica la existencia, no sólo deja convertidos en ens rationis a los universales, los géneros o las diferencias, sino también a la mente y al cuerpo humanos. Ahora el cuerpo-mente de cada persona es sólo un conjunto de movimientos y reposo materiales particulares, en el caso del cuerpo, y un conjunto de ideas mentales particulares, en el caso de la mente; y ambos son subconjuntos de los atributos Extensión y Pensamiento. Creo que esta es la gran iluminación de Spinoza, la que lo singulariza como pensador y la que lo distingue de Descartes y de otros cartesianos. Es la piedra angular en la que se apoya todo su sistema; de hecho, es la primera idea que expone Spinoza como corolario de su teología. En el Tratado breve, su formulación es: "Yo no entiendo en absoluto que el hombre, en cuanto consta de alma (mente) o cuerpo sea sustancia» (KV 97), "de ahí que todo cuanto tiene de pensamiento, no son más que propiedades del atributo pensante, que le hemos atribuido a Dios. Y, por otra parte, todo cuanto tiene de figura, movimiento y otras cosas, lo son igualmente del otro atributo que fue aplicado a Dios» (KV 98). La identidad de cada persona es, entonces, sólo un concepto, en realidad hay múltiples particulares en movimiento y cambio constantes, que sólo mantienen cierta relación entre ellos: «Si un cuerpo tiene y mantiene esa proporción, que es, por ejemplo, de 1 a 3, la mente y el cuerpo estarán igual que está ahora el nues-

12 Este largo escolio a la proposición II de la Ética III, por cierto, es una buena muestra de los argumentos típicos cartesianos expuestos por Spinoza frente a la concepción tradicional de la relación entre el alma y el cuerpo. Esta ignora la nueva ciencia anatómica y su estudio del funcionamiento del cuerpo - corporis fabrica-, que establece la relevancia y autonomía del cuerpo, minusvaloradas ambas por la antropología tradicional. De ahí que en E II, 13, escolio, se diga: "A partir de lo dicho, no sólo entendemos que la mente esté unida al cuerpo, sino también lo que debe entenderse por unión de mente y cuerpo. Sin embargo, nadie podrá entenderla adecuadamente, o sea, distintamente, si no conoce primero adecuadamente la naturaleza de nuestro cuerpo» (E 125), y que "cuanto más apto es un cuerpo que los demás para obrar o padecer muchas cosas a la vez, tanto más apta es su mente que las demás para percibir muchas cosas a la vez» (idem). Incluso avisa de la confusión entre ideas, palabras e imágenes, cuando sólo las ideas son mentales ya que las palabras y las imágenes pertenecen al cuerpo ( $c f$. E 172). 
tro, el cual está sin duda constantemente sometido al cambio, mas no tan grande que se salga de los límites de 1 a 3; sin embargo, cuanto cambia él, tanto cambia, a su vez, la mente» (KV 100, nota).

Así también se lee en E II, 2: «A la esencia del hombre no pertenece el ser de la substancia, o sea, no es una substancia lo que constituye la forma del hombre», cuyo corolario es: «La esencia del hombre está constituida por ciertas modificaciones de los atributos de Dios», en cuanto a la mente: «La mente humana es una parte del entendimiento infinito de Dios» (E 123), e igual en cuanto al cuerpo respecto a la Extensión. Y cada individuo se distinguirá de otro en tanto los distintos cuerpos que constituyen su cuerpo guarden «cierta relación» (E 129), tal como se aclara en los lemas IV y v de Ética II. Lo mismo respecto a la mente, como se recoge en la proposición XV de Ética II: «La idea que constituye el ser formal de la mente humana no es simple, sino compuesta de muchísimas ideas». De ahí que, si se pierde esa proporción, el individuo sea otro: «Ocurre a veces que un hombre experimenta tales cambios que difícilmente se diría de él que es el mismo» (E 307) ${ }^{13}$. Así que la perspectiva del Yo no es muy querida por Spinoza; él o piensa desde cada una de las ideas y cada uno de los movimientos del cuerpo, o desde Dios como totalidad infinita; incluso parece preferir la comunidad de individuos, ya religiosa ya política, a la unidad del yo, ya que este es entendido como un conjunto de ideas mentales y movimientos corporales sin referente ontológico relevante.

Las facultades humanas quedan eliminadas en tanto que serían realidades intermedias con autonomía ontológica, y rivales, de algún modo, a Dios, algo que Spinoza rechaza explícitamente: quienes «inventan residencias y moradas del alma ${ }^{14}$ suelen mover a risa o asco» (E 151), o "no hay en la mente ninguna facultad absoluta de entender, desear, amar, etc. De donde se sigue que estas facultades, u otras semejantes, o son completamente ficticias, o no son más que entes metafísicos, o sea, universales, que solemos formar a partir de los particulares» (E 168), o «en la mente no hay ninguna facultad absoluta de querer y no querer sino tan sólo voliciones singulares» (E 169). Su postura por tanto no es exactamente negar la libertad de la voluntad, sino negar la voluntad. En el Tratado breve había escrito: «La voluntad no es una cosa real en la naturaleza, sino tan sólo una ficción y, por lo mismo, no es necesario preguntar si la voluntad es libre o no" (KV 133). Igual con el entendimiento, ya que "la voluntad y el entendimiento son uno y lo mismo» ${ }^{15}$ (E 170). De

13 De algún modo, «toda la naturaleza es un solo individuo, cuyas partes, esto es, todos los cuerpos, varían de infinitas maneras, sin cambio alguno del individuo total» (E 132).

${ }^{14}$ Obsérvese que aquí, sí, Spinoza utiliza anima, no mens, porque está hablando de la antropología tradicional, que llena el alma de varias estancias o instancias.

${ }^{15} \mathrm{Si}$ el alma, la voluntad y el entendimiento fueran cosas realmente distintas, su relación no sería nada fácil; de ahí que Spinoza encuentre múltiples paradojas en la antropología tradicional ( $c f$. KV 132-133, nota 4). Por otro lado, esta tesis es explícitamente anticartesiana, aunque la diferencia de fondo no atañe, creo, a los hechos mismos, reconocidos por ambos, sino a las palabras. La discrepancia radica en si la voluntad/entendimiento es una facultad mental real o no ( $c f$. E 172-175). 
ahí que la misma necesidad que preside la naturaleza rija la relación entre voliciones particulares.

El desacuerdo con Descartes no radica, por ello, exactamente en que él defienda la libertad y Spinoza la necesidad. La conciencia de la libertad admitida por Descartes no es la que niega Spinoza porque es común a la experiencia humana, está presupuesta en el acto mismo de escribir libros para que la gente reforme su entendimiento y es la libertad a la que dedica su Tratado teológico-político; la discrepancia tampoco radica en que uno entienda la libertad como indecisión entre hacer o no hacer y el otro no, ya que ambos rechazan esta concepción de la libertad como de poca relevancia; para ambos -como para los clásicos-, una persona libre lo es porque no obedece, como los esclavos, sino que manda, como los señores. La separación entre ambos se da a otro nivel: Descartes considera que cada persona puede mandar sobre sí mismo, algo que lo acerca a Dios; Spinoza, sin embargo, niega que cada persona sea autónoma para mandar sobre sí misma, el sabio reconoce en ese poder la acción de Dios, es el ignorante el que se cree causa de sus actos, ignorando la causa única, total y absoluta, que es Dios. Tanto Spinoza como Descartes comparten la conciencia del poder de la razón sobre las pasiones, discrepan sólo en la interpretación de esa experiencia: Descartes sitúa esa potestad en cada persona, Spinoza la sitúa en Dios mismo; algo, por cierto, que, en última instancia también acepta Descartes, pero sin restarle entidad ontológica y moral a cada persona. Ahí, creo, está la clave de la diferencia entre ambos.

\subsection{IDEAS DE COSAS, COSAS IDEADAS}

La teoría del conocimiento spinoziana está centrada en la unión cognoscitivo-ontológica con Dios. De ahí que, cuando distingue distintos niveles de conocimiento, su objetivo sea destacar el grado superior. Los errores proceden del testimonio personal o de la experiencia o de las opiniones, incluso de la fe verdadera, sólo el conocimiento claro y distinto supone "una unión inmediata con la cosa misma" (KV 106, nota 1). La fe verdadera «nos muestra sin duda qué le corresponde ser a la cosa, pero no qué es en realidad. Y este es el motivo por el cual la fe no nos hace unir con la cosa creída. Digo, pues, que ella nos dice qué le corresponde ser a la cosa, y no qué es. Entre lo uno y lo otro existe una gran diferencia» (KV 107). Y esa es, claro, la diferencia que Spinoza persigue porque él tiene como objetivo unirse a Dios -más que, digamos, hacer avanzar el conocimiento humano, que era el objetivo de Descartes-. Y esto afecta incluso a la concepción de las ideas y del juicio. Para Spinoza, la diferencia ontológica entre las ideas y las cosas de que son ideas pasa a un segundo plano frente la diferencia real entre una idea adecuada y una idea inadecuada: la primera acoge al objeto de modo total, la segunda de modo superficial o parcial. Por tanto, no todas las ideas son iguales entre sí, su igualdad en tanto que ideas oculta la diferencia fundamental: en unas se hace presente el objeto mismo y ya no hay lugar para la duda ni para el error; en las otras sí, incluso se «puede pen- 
sar que se está en la verdad» (KV 129) ${ }^{16}$. La concepción de juicio también cambia con este enfoque, de modo que «jamás somos nosotros los que afirmamos o negamos algo de la cosa, sino que es la cosa misma la que afirma o niega en nosotros algo de sí misma» (KV 134). Las mentes débiles son aquellas que hacen juicios meramente verbales en base a «una ligera acción del objeto en ellas» (KV 135). La diferencia entre el sabio y el ignorante es, así, físico-psíquica. Finalmente, también la evidencia cambia ligeramente de estatus: el equilibrio cartesiano entre lo subjetivo y lo objetivo cae en Spinoza, claramente, del lado del objeto ya que algo no es verdadero porque sea evidente, sino que es evidente porque es verdadero: «Las cosas más claras de todas se dan a conocer a sí mismas y su verdad, de tal modo que sería una gran necedad preguntar cómo es uno consciente de eso. Pues, como se ha dicho que son las más claras, no puede haber jamás ninguna otra claridad por la que pudieran ser clarificadas» (KV 129).

En la Ética se reformulan estas ideas y se explica el origen de las nociones comunes y de los conceptos generales. Se recordará que para Descartes principios como el principio de no contradicción y otros eran innatos; pues bien, para Spinoza, proceden de las características comunes en los cuerpos: «Hay ciertas ideas o nociones comunes a todos los hombres, pues todos los cuerpos concuerdan en ciertas cosas, las cuales deben ser percibidas por todos adecuadamente, o sea, clara y distintamente» (E 153). En cuanto a conceptos como "ser», "cosa», «algo», «hombre», etc., lejos de tener privilegio cognoscitivo u ontológico alguno, no son más que ideas confusas que la mente construye por ser incapaz de recoger todos los matices de las cosas particulares, como prueba el hecho de que en cada persona son distintas (cf. E 155-156).

Me centraré, con todo, en la definición del tercer grado de conocimiento porque ilustra perfectamente la diferencia de talante entre Spinoza y Descartes. Es un grado de conocimiento, por cierto, más bien aludido que expuesto con claridad por Spinoza, cuya definición es pospuesta en numerosas ocasiones, tanto en el Tratado breve como en la Ética, algo así como si él prefiriera hablar de sus efectos a quien ya los conozca que hablar de colores a los ciegos. De hecho, la definición más completa se encuentra casi al final de la Ética, en la demostración de la proposición 25 de la parte v: «El tercer grado de conocimiento progresa, a partir de la idea adecuada de ciertos atributos de Dios, hacia el conocimiento adecuado de la esencia de las cosas. Cuanto más entendemos las cosas de este modo, tanto más entendemos a Dios y, por ende, la suprema virtud de la mente, esto es, que su potencia o naturaleza suprema, o sea, su supremo esfuerzo, consiste en conocer las cosas según el tercer género de conocimiento» (E 377). Sólo que se da la circunstancia de que ya Descartes había cerrado la meditación quinta de sus Meditationes de prima philosophia advirtiendo que sin Dios no hay verdad: «Y así veo muy claramente que la certeza y verdad de toda ciencia dependen sólo del conocimiento del verdadero Dios; de manera que, antes de conocerlo, yo no podía saber con perfección cosa alguna.

${ }^{16}$ Para la versión de estas cuestiones en la Ética, véase E II, proposición 43, escolio. 
Y ahora que lo conozco, tengo el medio de adquirir una ciencia perfecta acerca de infinidad de cosas: y no sólo acerca de Dios mismo, sino también de la naturaleza corpórea, en cuanto que ésta es objeto de la pura matemática, que no se ocupa de la existencia del cuerpo ${ }^{17}$. El talante es, con todo, distinto. Es sabido que Descartes se esforzó, con mayor o menor fortuna, en construir un completo sistema científico alternativo al tradicional -del cual Dios era el marco general-, mientras que Spinoza meditó sobre la persona perfecta y, seguramente, se esforzó él mismo en ese camino personal de perfección -en el cual Dios ocupa el lugar central, casi único-, que compartiría con un grupo de elegidos.

\subsection{Pasiones, PASIONES, PASIONES}

La otra vertiente de la teoría del conocimiento spinoziana tiene que ver con el origen y, en su caso, el control de las pasiones. En efecto, de los grados inferiores del conocimiento proceden las pasiones y sólo del grado superior procede la beatitud. Con todo, el Tratado breve sigue de cerca los análisis cartesianos de Las pasiones del alma, aunque, como se verá, con talante distinto.

Descartes había establecido seis pasiones primitivas -admiración, amor, odio, deseo, gozo y tristeza- y muchas otras derivadas, y había estudiado pacientemente, en cada una de ellas, "la agitación con que los espíritus mueven la pequeña glándula que está en medio del cerebro» (P 131) y el diferente movimiento de la sangre, de la agitación del corazón, del pulso, de la digestión de los alimentos en el estómago, etc.; también los signos exteriores de cada una de las pasiones, como los diferentes movimientos de los ojos y del rostro, o su cambio de color, o los temblores, la languidez, las risas, lágrimas, gemidos, suspiros, etc. Al comienzo, además, había avisado de que su planteamiento no iba a ser «explicar las pasiones como orador, ni tampoco como filósofo moral, sino solamente como físico» (P 49-50). Pues bien, Spinoza adopta claramente el punto de vista de un filósofo moral: «Comenzaremos a investigar qué pasiones son para nosotros racionales y cuáles irracionales» (KV 106), o "el tercer efecto de la verdadera fe es que nos proporciona el conocimiento del bien y del mal, y nos señala todas las pasiones que hay que destruir. Y, como antes hemos dicho que las pasiones que surgen de la opinión están sujetas a grandes males, merece la pena que veamos ahora cómo ser cernidas, a fin de que veamos qué hay de bueno y qué de malo en ellas [...] a fin de lograr saber cuáles debemos escoger y cuáles desechar» (KV 107). Así que cuando Spinoza habla de la admiración, del amor, del odio, del deseo, de la alegría, de la tristeza, etc., su planteamiento difiere ostensiblemente del cartesiano.

17 René Descartes, Meditaciones metafísicas, edición de Vidal Peña, Oviedo, KrK, 2004, p. 220. También en sus respuestas a las segundas objeciones, Descartes reconoce que un ateo podría saber geometría pero no «mediante una ciencia verdadera y cierta [...] supuesto que se trata de un ateo, no puede estar seguro de no engańarse en aquello que le parece evidentísimo» (ibid., p. 340). 
Baste un ejemplo, dado que un estudio pormenorizado que compare cada pasión y analice sus diferencias respecto a las reformulaciones de la Ética cae fuera de este artículo. Cuando Descartes habla del amor, lo presenta como «una emoción del alma causada por el movimiento de los espíritus que le incita a unirse a voluntad a los objetos que parecen serle convenientes» (P 151), y considera irrelevante la distinción -moralista- entre amor de concupiscencia y amor de benevolencia, o entre el amor a la ambición, al dinero, al vino o a una mujer. Spinoza, sin embargo, distingue entre el amor en función de los objetos a que se una. Si el objeto es perecedero, será perjudicial, afirma incluso que «sin duda es miserable aquel que se une con una cosa perecedera» (KV 111), o "está claramente desvelado el veneno y el mal que está metido y escondido en el amor a esas cosas. Pero aún lo vemos de forma incomparablemente más clara si advertimos de qué bien tan magnífico y excelente somos separados a causa del gozo de ellos» (idem). Si el objeto es eterno e imperecedero, pero no lo es por sí mismo, es mejor que amar un objeto perecedero, pero es sólo un paso más en el camino que lleva a amar a Dios, «en el cual, por ser perfecto, debe descansar necesariamente nuestro amor» (KV 112); el conocimiento supone «la manifestación inmediata del objeto mismo al entendimiento. De ahí que, si el objeto es excelente y bueno, la mente se unirá necesariamente con él, tal como hemos dicho también de nuestro cuerpo» (KV 153).

En la Ética, Spinoza olvida por completo el aspecto fisiológico de las emociones y se centra en su definición y ordenamiento lógicos. Como afectos primitivos elige el deseo, la alegría y la tristeza -cuando en el Tratado breve partía del deseo, el amor y el odio-, a partir de los cuales define hasta cuarenta y ocho afectos derivados -por treinta y dos en el Tratado breve-, entre los que se encuentran desde la desesperación o el menosprecio hasta la crueldad o la generosidad, pasando por el vituperio, la consternación o el contento de sí mismo. Aquí llama la atención el aviso contenido en el prefacio a la parte III, donde Spinoza se distancia de los moralistas que no se esfuerzan por entender los afectos sino que los detestan y ridiculizan y consideran la naturaleza humana como fuente de los vicios; él, sin embargo, defiende que en la naturaleza todo es necesario y perfecto, por lo que expondrá los afectos «como si fuese cuestión de líneas, superficies o cuerpos» (E 182); lo cual lo aleja de ciertos moralistas, ciertamente, pero también lo mantiene alejado del enfoque cartesiano, más científico y descriptivo. En el prefacio a la parte IV, escribe: «Me he propuesto demostrar [...] qué tienen de bueno o de malo los afectos» (E 262); en el prefacio a la parte v: "Entenderé por "bueno" aquello que sabemos con certeza ser medio para acercarnos cada vez más al modelo ideal de naturaleza humana que nos proponemos. Y por "malo", en cambio, entenderé aquello que sabemos ciertamente que nos impide referirnos a dicho modelo. Además, diremos que los hombres son más perfectos o más imperfectos según se aproximen más o menos al modelo en cuestión» (E 267). De hecho, me parece que fueron sus juicios sobre ciertas pasiones -y sobre Dios y la inmortalidad- los que motivaron las fuertes reacciones en su contra por parte de algunos de sus primeros lectores. 


\section{5. ¿INMORTALIDAD? CONTRA LA RELIGIÓN TRADICIONAL}

Es sabido que Descartes, cuando encomendó sus Meditaciones a los teólogos de la Sorbona parisina, les anunció que había demostrado la inmortalidad del alma; después tuvo que reconocer que sólo había mostrado la distinción real entre el cuerpo y el alma humanos, y que tenía que dejar su separación efectiva por Dios a la fe. Su concepción se alejaba de la habitual porque tal separabilidad se la concedía sólo a las funciones superiores del alma, esto es, a las que -aparentemente- no dependían del cuerpo, como pensar en Dios, las matemáticas o pensamiento abstracto; por ello, las pasiones, la memoria o las percepciones estaban fuera de consideración. Con todo, esa cuestión, como la de Dios, era para él meramente el marco para sus estudios de la naturaleza, de las percepciones o de la geometría. También Spinoza habla de la inmortalidad, pero, en su caso, es una cuestión central, como Dios; y también en su caso se alejó de las concepciones tradicionales.

En el Tratado breve escribe: «En cuanto la mente sólo está unida con el cuerpo y el cuerpo llega a perecer, también ella debe perecer ya que, al faltar el cuerpo, que es el fundamento de su amor, ella debe perecer con él. En cuanto ella está unida con una cosa que es y que permanece inmutable, también ella deberá, por el contrario, permanecer inmutable» (KV 156-157). De modo que, en tanto que la mente es el conjunto de ideas mentales, la suerte de cada idea irá pareja a la del objeto del que es idea: si este perece, la idea también, si el objeto es imperecedero la idea también. Dado que sólo Dios es imperecedero, sólo las ideas que se unan a Dios serán por tanto inmortales, y esas ideas serán las mismas en todas las personas que logren unirse a Dios. Como se ve, es una concepción de la inmortalidad donde confluyen todos los principios gnoseológico-ontológicos expuestos anteriormente y que nada, o muy poco, tiene que ver con la inmortalidad tradicional, dado que las ideas de lo eterno no lo son de un yo particular que «mereciera» premio o castigo.

En Ética v, 23 vuelve a hablar de la inmortalidad, pero dándole un aspecto poco reconocible. Las que son eternas son las ideas que componen la mente en tanto que son modos del atributo Pensamiento, que es infinito y eterno; además, la eternidad no tiene que ver con el tiempo, que no está presente en Dios, «mas no por ello dejamos de sentir y experimentar que somos eternos» (E 376). Esto es, Spinoza no tiene en mente la inmortalidad de la que se hablaba en los púlpitos y que tanto representaban los pintores y los músicos de su época, sino la sensación de inmortalidad, de la que el sabio goza al ejercer el tercer grado de conocimiento y al contemplar las demostraciones matemáticas o éticas. Además, el cuerpo del sabio le permite ese gozo dado que tiene una mente "cuya mayor parte es eterna» (E 388) y en nada piensa menos que en la muerte y en los premios o castigos del más allá, que eran precisamente los pilares de la religión. De ahí que Spinoza avise que la moralidad y la religión no han de basarse en la esperanza, el miedo, las penas o los castigos asociados a una duración pálidamente física tras la muerte. Según él, la utilidad es fundamento suficiente para las leyes del Estado que regulen la moralidad social. 
De modo que no sólo era el Dios spinoziano el que presentaba un aspecto muy distinto de su rostro habitual ${ }^{18}$. Ahora Spinoza defiende que las pasiones no son propias de Él -cuando, por contra, los cristianos reviven cada año la Pasión del Cristo Jesús- y que Dios no ama a los humanos (KV 157), ni hubo Decálogo (KV 158) ni conversación con Moisés (KV 160), tampoco hay demonios (KV 162); además, el verdadero infierno son las malas pasiones y a Dios no hay que temerle (KV 139); la religión auténtica le parece que es seguir las leyes de la naturaleza (KV 140). Y, en su análisis de los afectos humanos, rechaza todos los que habitualmente cultivaban los predicadores de todos los grupos religiosos: la superstición (E 328, 348), la abyección (E 344), las lágrimas, el miedo, la impotencia, la desgracia (E 312); mientras que la risa, los perfumes, el teatro y la música, tan criticados desde el púlpito, sí son buenos, según Spinoza (idem); también son malos la tristeza, la humildad, el arrepentimiento, la conmiseración, etc.; y lo que es sagrado para una religión es profano para otras (E 252). Motivos más que suficientes, me parece, para los exabruptos de los que fue objeto Spinoza desde el comienzo ya que parecen opiniones dirigidas expresamente contra las religiones de su época. En estas cuestiones, Descartes cultivó siempre la prudencia, pero Spinoza las consideraba irrenunciables, sabiendo que eso lo convertía en un pensador no popular, algo de lo que era perfectamente consciente. De su ideal de persona perfecta, sabia o santa dice, en la última frase de la Ética: «Todo lo excelso es tan difícil como raro» (E 392).

\subsection{El santo, el sabio, el perfecto, el esclavo de Dios}

Si la antropología cartesiana conducía al estudio del cuerpo humano y de la fisiología de las emociones, la antropología spinoziana, como se ve, conduce al cultivo de ciertos momentos físico-mentales - los de gozo, contento de sí mismo, felicidad, beatitud- que son bien conocidos en distintas tradiciones filosóficas, religiosas y místicas. Spinoza los convierte en el eje de su planteamiento ya que, en cualquier asunto que trata, siempre tiene en mente a Dios y a la unión con Dios, a la que llama salvación, renacimiento, sabiduría, etc. Por mor de la brevedad, eludiré las citas y presentaré no sólo su descripción de la persona perfecta en contraposición a la persona ignorante, sino las cuestiones parejas: 1) si la razón se basta para el control de las malas pasiones y 2) si es posible conocer el bien y aprobarlo pero hacer el mal. Las respuestas spinozianas serán: 1) la razón no se basta, es necesario Dios y 2) si se conoce realmente el bien, se hace necesariamente.

En el Tratado breve, Spinoza presenta al perfecto como aquel que se sabe parte de la naturaleza, que nada puede hacer por sí mismo para su salvación sino que se siente siervo y esclavo de Dios; por eso evita la presunción, el odio a los demás,

18 Sobre su concepción de la divinidad escribe: «No nos preocuparemos demasiado de las imágenes que los hombres tienen comúnmente de Dios, sino que tan sólo investigaremos qué es lo que los filósofos nos saben decir de él» (KV 89). 
la parcialidad, la tristeza, la desesperación, la envidia, el miedo, el temor a Dios; cuando ayuda al prójimo lo hace por necesidad, y ayuda también a los impíos; la suprema beatitud consiste en el amor-unión con Dios, un goce intelectual que consiste en la contemplación de las cosas incorpóreas; cuando llega Dios a la mente, todas las pasiones malas quedan arrinconadas, aunque nunca eliminadas, la razón por sí sola no se basta para ello; es, literalmente, un segundo nacimiento como efecto de la unión con un objeto imperecedero, que produce alegría, tranquilidad de ánimo, salvación y beatitud.

En Ética v, Spinoza sostiene que el sabio, aunque no tiene un control absoluto sobre las pasiones, es más poderoso que el ignorante. Su fuerza consiste en conocer; ahora bien, esa fuerza nada tiene de «espiritual» o «intelectual», como si fuera una instancia de otro mundo que actuara sobre las pasiones; es una fuerza que radica en las ideas de la razón, cuyo orden es el mismo que el orden de los movimientos del cuerpo, entre los que se encuentran también los movimientos de las pasiones; así, conocer, esto es, tener ideas adecuadas, implica que en el cuerpo las pasiones pierden -es más, ya han perdido- terreno, pero ni desaparecen ni pierden su fuerza. Para Spinoza, conocer implica al cuerpo, no es algo "angelical»; de ahí que el sabio viva en alegría, en el sentido de expansión físico-psíquica. Así, la muerte no es nada, pensar en ella sólo debilita; y no se puede querer lo bueno y hacer lo malo porque, para Spinoza, querer lo bueno implica que lo bueno ha ganado ya la partida, por lo tanto, se hace. Quienes hablan como la Medea de Ovidio en sus Metamorfosis, viI, 20 -vide meliora proboque deteriora sequor (E IV 17, esc.) [veo lo mejor y lo apruebo pero sigo lo peor]- es porque en ellos el conocer es todavía débil, tienen ideas inadecuadas ${ }^{19}$. La práctica y el ejercicio son muy importantes para ordenar las ideas y fortalecer las adecuadas ( $c f . \mathrm{Ev}, 10$, escolio) ${ }^{20}$. Cuando estas son más que las inadecuadas, la persona vive en lo eterno, deja a un lado lo particular y cultiva la amistad de quienes, como ella, adoptan a menudo el punto de vista de la divinidad, y la unión alegre y gozosa con la naturaleza divina y omnificiente. Se liberan así también de las ataduras de los prejuicios, de la superstición y de la observancia de las reglas de los distintos grupos religiosos; son esclavas, pero de Dios, lo que supone la máxima libertad. Por eso Spinoza acaba su Ética recordando que el sabio no controla las pasiones por la fuerza de su razón exclusivamente, sino por la presencia de Dios: «En virtud de gozar la mente de ese amor divino o beatitud tiene el poder de reprimir las concupiscencias; $y$, puesto que la potencia humana para reprimir los afectos consiste sólo en el entendimiento, nadie goza entonces de esa beatitud porque reprima sus afectos, sino que, por el contrario, el poder de reprimir sus concupiscencias brota de la beatitud misma» (E 392).

19 También Descartes había distinguido entre almas fuertes y débiles en función de «juicios firmes y precisos respecto al conocimiento del bien y del mal, según los cuales ha resuelto conducir las acciones de su vida» (P 125). Véase también P 126.

20 También Descartes insistió en la importancia de la práctica en parecidos términos, $c f$. P 118-120. 


\section{LA CRÍTICA DE SPINOZA A DESCARTES EN ÉTICA, V, PREFACIO}

Spinoza se guarda su crítica explícita a Descartes - la más conocida- para el prefacio a Ética v, aunque la había anunciado en el prefacio a Ética III, donde llama a Descartes «celebérrimo» (E 182). Es importante destacar el contexto de la crítica para evitar las malas interpretaciones al uso. En E III Spinoza critica a quienes entienden al ser humano como «un imperio dentro de otro imperio» (E 181), cuando, para él, el ser humano no es causa de sus actos y, por tanto, tampoco responsable de sus vicios; en esa línea nombra a Descartes como quien "cree que la mente tiene una potencia absoluta sobre sus acciones» (idem). Ese es también el contexto en $\mathrm{E} v$, donde Spinoza nombra a los estoicos, los cuales creyeron «que los afectos dependen absolutamente de nuestra voluntad y que podemos dominarlos completamente» (E 353), opinión «muy próxima a la de Descartes» (idem). De modo que la cuestión no es cómo actúa la mente en el cuerpo sino si la voluntad, o la razón, tienen un poder absoluto sobre los afectos. Tras el repaso a la antropología de ambos, se ve claramente que Spinoza discrepa con Descartes, y con la antropología tradicional, en esos dos puntos: ni la voluntad es una facultad con poder de suyo ni la potencia de la razón es absoluta.

Se da la circunstancia, sin embargo, de que Spinoza cita pormenorizadamente Las pasiones del alma, donde Descartes habla ${ }^{21}$ de la importancia de la glándula pineal para la unión de la mente ${ }^{22}$ y el cuerpo, lo cual ha dado pie a pensar que ahí radica su crítica a Descartes. Sin embargo, basta cotejar esos pasajes con los correspondientes del Tratado breve $e^{23}$ para comprobar que también Spinoza piensa que la mente actúa sobre el cuerpo y este sobre la mente a través de los espíritus animales y que, cuando hay movimientos contrarios, se produce la sensación de angustia, lo que muestra la íntima unión de la mente con el cuerpo. De modo que no es ahí donde está la discrepancia, sino en la conclusión cartesiana que Spinoza parafrasea: «No hay alma tan débil que no pueda, estando bien guiada, adquirir un poder absoluto sobre sus pasiones» (P, art. 50), donde la palabra que molesta a Spinoza es «absoluto», matiz unido al presupuesto cartesiano de que «la determinación de la voluntad depende de nuestra sola potestad» (E 355), principio donde lo que molesta a Spinoza es «nuestra sola» potestad; finalmente la conclusión sería que «adquirimos un imperio absoluto sobre nuestras pasiones", algo que Spinoza no puede aceptar dado que Descartes, en ambos matices, olvida a Dios.

Spinoza se pregunta «qqué entiende por unión de mente y cuerpo?, ¿qué concepto claro y distinto tiene de la íntima unión de un pensamiento y una pequeña

${ }^{21}$ Cf. P 10, 30-36, 44, 50.

22 Por cierto, Spinoza escribe «animam seu mentem» para indicar que, aunque Descartes habla de «alma», él sabe que quiere decir «mente», palabra que el mismo Spinoza, como buen cartesiano, utiliza en toda su obra. La misma oscilación se da en KV, al comienzo de la parte segunda. Este matiz ha escapado a los traductores, tanto contemporáneos como actuales.

${ }^{23}$ Cf. KV 144-145, 148. 
porción de cantidad? Quisiera, ciertamente, que hubiese explicado dicha unión por su causa próxima. Pero había concebido la mente como algo tan distinto del cuerpo que no pudo asignar ninguna causa singular ni a esa unión ni a la mente misma, y le fue necesario recurrir a la causa del universo entero, es decir, a Dios» (E 356). Además, «como no hay proporción entre la voluntad y el movimiento, no puede haber tampoco comparación entre la potencia o fuerza de la mente y la del cuerpo, y, por consiguiente, las fuerzas de éste nunca pueden estar determinadas por las fuerzas de aquella» (idem). Finalmente, la glándula no recibe todos los nervios y no puede «ser movida con tanta facilidad y de tantos modos» (E 357).

Considero que estas críticas no ponen en cuestión la relación cartesiana mente-cuerpo - tal como hicieron Pierre Gassendi e Isabel de Bohemia-, sino la posición privilegiada, el papel protagonista, de la glándula pineal en mitad del cerebro como un centro de poder autónomo para regir el movimiento de los espíritus animales de un modo que, ciertamente, Descartes explica forzando su hipótesis y que, entendido literalmente, da lugar a la ironía de Spinoza. Él no pone en duda la unión, pero quiere que se explique bien -un lugar tan pequeńo no puede tener una confluencia de movimientos, a veces contrarios, tan grande-. Es más, creo que Spinoza resuelve a su modo las paradojas puesto que, al ser más claro que Descartes, establece que sólo hay un Dios, sólo hay una Naturaleza, sólo hay un hecho, que puede ser entendido ya desde la mente/Pensamiento ya desde el cuerpo/Extensión, pero no es necesario ese punto físico-psíquico de «intercambio». La glándula pineal sería, además, la representación, dentro del cuerpo, de la voluntad o el entendimiento de cada persona entendidos como facultades con suficiencia ontológica y con poder autónomo y libre -como un dios en pequeño-, algo que Spinoza entiende como incompatible con el poder único e inmanente de Dios. Spinoza prefiere hablar de poder "parcial»: "Cada cual tiene el poder -si no absoluto, al menos parcial- de conocerse a sí mismo y conocer sus afectos clara y distintamente, y, por consiguiente, de conseguir padecer menos por causa de ellos» (E 360).

\section{CONCLUSIÓN}

Espero haber mostrado que se puede volver a los textos originales de los filósofos y explicarlos sin la ayuda de las tan peligrosas etiquetas y clasificaciones filosóficas, puestas en circulación desde la proliferación de las Historias de la Filosofía, con claro sesgo nacional incluso continental, hace cien ańos, cuando, sintiendo el positivismo como una amenaza, la filosofía se reinventó a sí misma, pero que han dado lugar a una interminable lista de falsos problemas. También, confío, la necesidad de una nueva lectura de los textos de Descartes y de Spinoza que atienda a la novedad que supuso el descubrimiento de lo mental como realidad con entidad propia y ajena por completo a lo físico, lo que supuso, a la vez, restituir al cuerpo todas las características que la tradición le había quitado y colocado en el alma. Es el alma la gran perdedora de esta revolución conceptual, el cuerpo y los animales los grandes ganadores, y lo mental, tan escurridizo, el nuevo descubrimiento no del todo bien asentado en la tradición cartesiana. 
En este marco general común, la diferencia entre Descartes y Spinoza es bastante ostensible. Descartes escribe fundamentalmente como médico, estudia la anatomía del cuerpo, especialmente el cerebro, la fisiología de las emociones y el mecanismo de la visión; sin descuidar el aspecto mental-psicológico, campo donde se muestra como un fino observador de los mecanismos mentales. Su explicación de la separación de lo extenso y el pensamiento quedó, no obstante, sujeta a interpretaciones varias, dado que el tema era nuevo, el vocabulario difícil y el terreno resbaladizo. Spinoza, siguiendo los pasos de su maestro, formula con más claridad la relación pensamiento-materia entendida como dos puntos de vista alternativos sobre una única realidad; de ahí que -en su Ética, no en el Tratado breve-pueda leer con ironía los intentos cartesianos -ciertamente imaginativos-donde este proyecta sobre el movimiento de los corpúsculos que animan y sensibilizan el cuerpo todas las variaciones de las pasiones humanas tal como se experimentan habitualmente; pero puede hacerlo, sobre todo, porque su enfoque es distinto: él quiere clasificar y definir las pasiones-afectos más como lógico que como médico para poder, como teólogo-moralista, juzgar qué pasiones ha de fortalecer el sabio y cuáles debilitar. Descartes hace ciencia, en su doble vertiente teórico-práctica, Spinoza vive sus planteamientos experiencialmente, de ahí la importancia del amor como unión con lo que le asegure renovación físico-psíquica y gozo especial. Descartes se presenta como alternativa a la explicación de la naturaleza y del ser humano con vocación mayoritaria, mientras que Spinoza escribe para los pocos que sintonizan con él; de manera que, si desconociéramos su obra política, podríamos pensar que era un místico, con una experiencia muy directa del renacimiento asociado a las experiencias religiosas intensas del tipo de las vividas por Miguel Servet o que su ideal sería vivir en una sociedad de intelectuales-amigos, reducida a fuerza de excelente. Eso le permite ser coherente sin prudencia: del mismo modo que rechazó las proyecciones humanas sobre Dios y las proyecciones humanas sobre la naturaleza, también rechaza las proyecciones humanas sobre el propio ser humano cuando decimos que tenemos voluntad, entendimiento, que somos libres, en el sentido de ser un poder autónomo, y que somos personalmente duraderos, esto es, inmortales.

El escolio a la proposición décima de E II, donde Spinoza critica a quienes «no son lo bastante consecuentes consigo mismos», me parece que resume bien la diferencia de talante entre Descartes y Spinoza; ante la imposibilidad de citarlo completo, elijo este fragmento: «Al considerar las cosas de la naturaleza, han pensado en todo menos en la naturaleza divina, y, al intentar más tarde considerar ésta, no han podido valerse de aquellas primeras ficciones suyas sobre las que habían construido el conocimiento de las cosas de la naturaleza, dado que de nada les servían para conocer la naturaleza divina. Y así no es de extrañar que hayan incurrido en contradicciones una y otra vez» (E 122). Porque no es lo mismo tener a Dios como marco general de las investigaciones propias que como centro, objetivo y referencia constante para tu propia vida.

Unas palabras, finalmente, sobre el modo que Spinoza eligió para dar a conocer sus planteamientos, como prólogo a unas reflexiones finales. La escritura de Spinoza oscila entre la presentación geométrica, que avanzó Descartes al final de sus respuestas a las segundas objeciones a sus Meditaciones, y el género que él inventó en 
sus Pensamientos metafísicos: capitulitos que se siguen con férrea lógica. Este nuevo tipo de discurso filosófico lo puso brillantemente en práctica en los treinta y dos capítulos del apéndice a Ética Iv. Se ha de notar, además, que el propio texto presentado geométricamente está trufado de presentaciones, escolios y resúmenes finales. En cualquier caso, la redacción de ambos tipos de texto -y su lectura y comprensión- son un buen ejemplo de alto trabajo intelectual, asociado a sensaciones físicas de poder mental y expansión física, alejamiento de preocupaciones ambientales y corporales, y concentración en la secuencia necesaria de las ideas. Características todas ellas que encajan con el tercer grado de conocimiento spinoziano. Se podría así decir que la misma concepción y redacción de la Ética constituyó una práctica de su propuesta ontometodológica.

Aplicando el principio spinoziano de que «la idea de Pedro que existe en Pablo [...] revela más bien la constitución del cuerpo de Pablo que la naturaleza de Pedro» (E 136-137), veamos qué conocimiento del propio Spinoza nos revelan sus planteamientos. En primer lugar, si aceptamos que el Dios del que habla es más bien un ens rationis que una realidad real, habría que decir que el objeto eterno e imperecedero al que, sin duda, se sintió unido en numerosas ocasiones era un producto de su propia mente en momentos psíquicos especiales; la intensidad de tales momentos se mide por la intensidad de su obra, del mismo modo que la experiencia de estar en posesión de lo que ahora llamaríamos una mente excepcional y poderosa -que le permitía entender, desde joven, mejor y más rápido que los demás las partes más abstrusas de la teología bíblica, de la metafísica escolástica y de la física cartesiana- le sirvió de guía en sus planteamientos. En esa línea, Spinoza antepone lo general a lo particular, tanto en su vida como a nivel social y político. En segundo lugar, Spinoza pertenecería al grupo de quienes, ante los avatares y oscilaciones de la vida, se calman y aceptan todo lo que ocurre cuando entienden que lo ocurrido ha sucedido de forma necesaria, de modo que no cabe ni pensar en que podía haber sido de otro modo ni culparse por haber actuado como se ha actuado; fuera quedan, por tanto, el miedo y la esperanza ante el futuro o ante la muerte, los remordimientos por el pasado y el honor y la gloria por lo hecho en el presente. Este grupo de humanos es reducido, ciertamente, pero sus propuestas gozan, desde la Grecia clásica, de un prestigio indiscutible.

Finalmente, y unido a esto último, Spinoza se incluye entre quienes no se las arreglan bien con «un amor excesivo hacia una cosa que está sujeta a muchas variaciones y que nunca podemos poseer por completo. Pues nadie está inquieto o ansioso sino por lo que ama, y las ofensas, las sospechas, las enemistades, etc., nacen sólo del amor hacia las cosas, de las que nadie puede, en realidad, ser dueño. Y así, concebimos por ello fácilmente el poder que tiene el conocimiento claro y distinto, y sobre todo ese tercer género de conocimiento cuyo fundamento es el conocimiento mismo de Dios, sobre los afectos: si no los suprime enteramente, en la medida en que son pasiones, logra al menos que constituyan una mínima parte de la mente. Engendra, además, amor hacia una cosa inmutable y eterna, y que podemos poseer realmente, amor que, de esta suerte, no puede ser mancillado por ninguno de los vicios presentes en el amor ordinario, sino que puede ser cada vez mayor, ocupar el más alto grado de la mente y afectarla ampliamente» (E 373). 
Como se ve, todo un programa de vida, con fuertes, aunque escasas, irradiaciones. Entre estas destaca su influencia en Jorge/George Santayana, filósofo nacido en Madrid en 1863 y que se trasladó a los nueve años a Boston. En la Universidad de Harvard desarrolló su vida académica hasta que, en 1912, volvió definitivamente a Europa, renunciando a ser profesor de filosofía y eligiendo la filosofía como forma de vida. Está enterrado en Roma, donde murió en 1952. Siempre se mantuvo fiel a la tradición humanista y moderna, nada escolástica y muy mundana; su brillante y fluido estilo enlaza con el de Locke y Hume y sus argumentos siguen los de Spinoza y Schopenhauer. Fue precisamente Santayana el encargado de festejar en La Haya en 1932 el 300 aniversario del nacimiento de Spinoza, con su charla «Ultimate Religion»".

RECIBIDO: noviembre 2018; ACEPTADO: octubre 2019

${ }^{24}$ Cf. George Santayana, «Religión última», traducción de Antonio Marichalar, Revista de Occidente 2, 1933, pp. 274. Disponible en https://dialnet.unirioja.es/servlet/articulo?codigo=4393006. 
